\title{
EE-1
}

PAPER - OPEN ACCESS

\section{Perencanaan dan perancangan fasilitas umum yang berkelanjutan pada desa wisata Tongging}

\author{
Author $\quad$ : Nurlisa Ginting dan Syahrial Effendi \\ DOI $\quad: 10.32734 /$ ee.v3i1.861 \\ Electronic ISSN $\quad: 2654-704 \mathrm{X}$ \\ Print ISSN : $2654-7031$
}

Volume 3 Issue 1 - 2020 TALENTA Conference Series: Energy \& Engineering (EE)

This work is licensed under a Creative Commons Attribution-NoDerivatives 4.0 International License.

Published under licence by TALENTA Publisher, Universitas Sumatera Utara 


\title{
jibiti \\ EE Conference Series 03 (2020) TALENTA Conference Series
}

-

Available online at https://talentaconfseries.usu.ac.id/ee

\section{Perencanaan dan Perancangan Fasilitas Umum Yang Berkelanjutan Pada Desa Wisata Tongging}

\author{
Planning and Designing Sustainable Public Facilities At The Tongging Tourism Village
}

\author{
Nurlisa Ginting ${ }^{a, b, c}$, Syahrial Effendi a 1
}

\begin{abstract}
${ }^{a}$ Program Studi Magister Teknik Arsitektur, Fakultas Teknik, Universitas Sumatera Utara, Jalan Perpustakaan Gedung J7 Kampus USU, Medan, 20155, Indonesia ${ }^{b}$ Kelompok Kerja Pariwisata Kawasan Danau Toba dan Pariwisata Berkelnajutan, Universitas Sumatera Utara, Jalan Dr. Mansyur Kampus USU, Medan, 20155, Indonesia

${ }^{c}$ Monitoring Centre for Sustainable Tourism Observatory (MCSTO) Universitas Sumatera Utara, Jalan Perpustakaan Gedung J7 Kampus USU, Medan, 20155,
\end{abstract} Indonesia

nurlisa@usu.ac.id, syrialeffendi@gmail.com

\begin{abstract}
Abstrak
Desa Tongging sebagai salah satu destinasi wisata di Kawasan Danau Toba yang memiliki potensi untuk dikembangkan. Sebagai syarat utama pengembangan Desa Tongging sebagai Desa wisata, harus memiliki fasilitas umum yang layak, aman, dan nyaman. Terutama pada fasilitas jalan, tempat parkir, toilet dan tempat ibadah Musholla. Namun sangat disayangkan masih ada fasilitas umum yang belum ada dan layak di Desa Tongging. Mengingat perkembangan desa ini, maka perlu dilakukan perencanaan dan perancangan fasilitas umum tersebut. Penelitian ini dilakukan dengan menggunakan data hasil observasi lapangan yang dianalisa secara kualitatif. Fasilitas umum terdiri dari sarana pokok keparawisataan, sarana penunjang, dan prasarana umum. Hal ini dilakukan dengan menganalisa kondisi yang ada saat ini berdasarakan studi kasus di desa yang sudah berhasil menyusun perencanaan serta perancangannya. Kajian ini menghasilkan konsep dan prinsip rencana dan rancangan fasilitas umum yang berkelanjutan di Desa Tongging.
\end{abstract}

Kata kunci ; Fasilitas umum , Desa wisata Tongging

\begin{abstract}
Tongging Village as one of the tourist destinations in the Lake Toba region that has the potential to be developed. As the main requirement for developing Tongging Village as a tourist village, it must have decent, safe and comfortable public facilities. Especially on road facilities, parking lots, toilets and places of worship. But it is unfortunate that there are still public facilities that do not yet exist and are feasible in Tongging Village. Considering the development of this village, it is necessary to do the planning and design of these public facilities. This research was conducted using data from field observations that were analyzed qualitatively. Public facilities consist of principal tourism facilities, supporting facilities, and public infrastructure. This is done by analyzing the current conditions based on case studies in villages that have succeeded in compiling their plans and designs. This study produced the concepts and principles of the plan and design of sustainable public facilities in Tongging Village.
\end{abstract}

Keywords ; Public facilities, Tongging tourism village

\section{Pendahuluan}

Kawasan Danau Toba telah menjadi suatu destinasi pariwisata berkelas Internasional ditandai dengam mendapatkan sertifikasi dari UNESCO Global Geopark (UGG) pada 31 Agustus 2019 dan sekaligus menjadi anggotanya. Untuk mendukung hal tersebut pemerintah menetapkan Danau Toba masuk menjadi salah satu dari 10 lokasi kawasan strategis nasional (KSN) yaitu Kawasan Strategi Pariwisata Nasional Danau Toba. Terdapat delapan Kabupaten/Kota yang termasuk dalam kawasan Danau Toba yang salah satunya adalah Kabupaten Karo.

Desa Tongging yang berada di tepi Danau Toba adalah salah satu desa yang berada di Kecamatan Merek, yang merupakan salah satu kecamatan di kabupaten Karo. Desa ini memiliki potensi untuk dikembangkan untuk meningkatkan pendapatan masyarakatnya. Salah satu cara menaikkan pendapatan masyarakat adalah sektor Pariwisata. Salah satu bentuk wisata unggulan daerah yang sangat

(C) 2020 The Authors. Published by TALENTA Publisher Universitas Sumatera Utara

Selection and peer-review under responsibility of Seminar Nasional Kearifan Lokal V 2020

p-ISSN: 2654-7031, e-ISSN: 2654-704X, DOI: 10.32734/ee.v3i1.861 
popular dikembangkan dewasa ini adalah desa wisata (Hermawan, 2016) [1]. Desa tongging terletak pada Kecamatan Merek, Kabupaten Karo, Sumatera utara yang memiliki luas wilayah $450 \mathrm{~km} 2$ berjarak sekitar $40 \mathrm{~km}$ dari kota Brastagi.

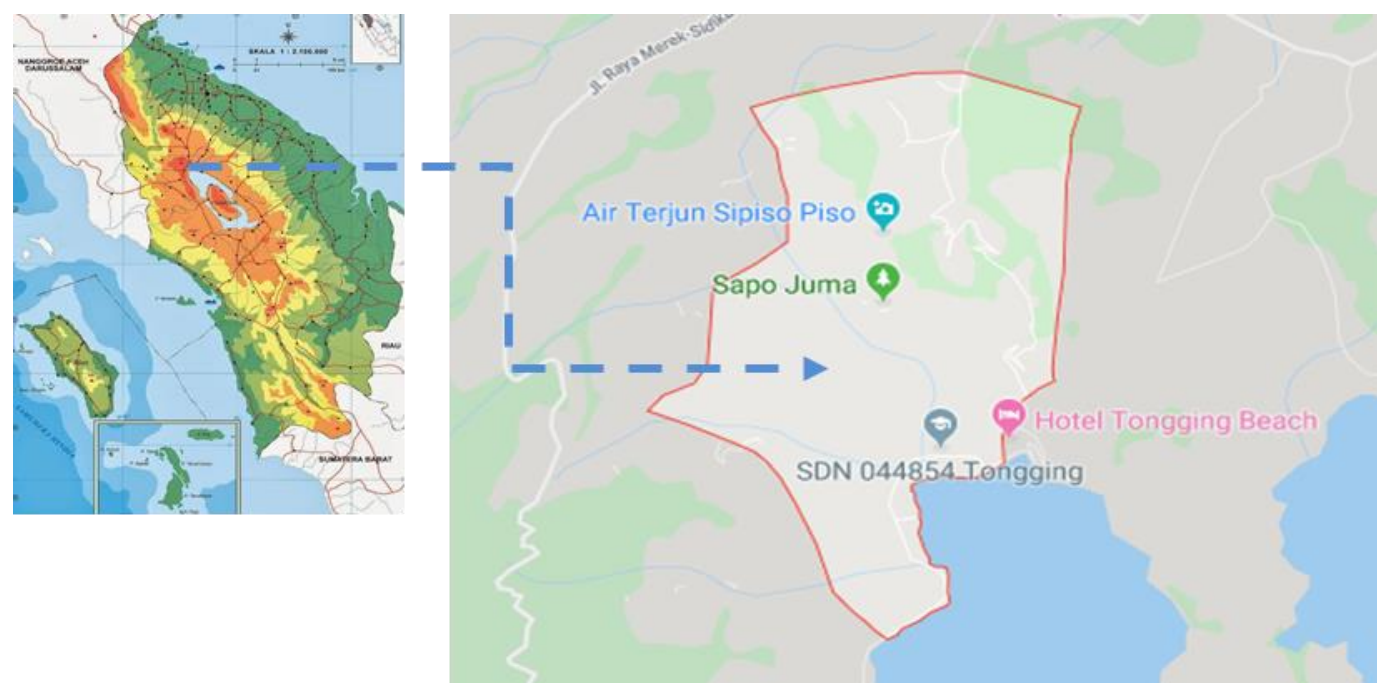

Gambar 1. Peta sebaran lokasi wisata Kawasan Tongging (sumber : Google map)

\section{Tinjauan Pustaka}

\subsection{Desa Wisata}

Sebuah desa wisata adalah daerah tujuan wisata dimana faktor daya tarik wisata didukung oleh fasiitas umum , fasilitas pariwisata, aksesibilitas yang tersaji dalam suatu kemasan dengan adat istiadat dan tradisi yang berlangsung sehari-hari di desa tersebut (Nuryanti, 1993) ${ }^{[1]}$. Sedangkan menurut terminologi yang lain disebutkan desa wisata sebagai suatu perpaduan antara atraksi , akomodasi dan fasilitas pendukung yang disajikan dalam suatu kesatuan kehidupan masyarakat pedesaan. Untuk menjadikan sebuah desa sebagai desa wisata semua sumber daya yang ada harus dalam kondisi yang mantap agar wisatawan mau datang ke desa itu.Tanpa infrastruktur yang baik maka desa wisata tersebut tidak dapat berkembang.Untuk menjadi tujuan wisata maka desa wisata wajib memiliki fasilitas yang memanjakan pengunjung yang datang ke desa tersebut.

Menurut teori yang lain, desa wisata merupakan pengembangan suatu desa dengan memanfaatkan kemampuan unsur-unsur yang ada dalam masyarakat dan desa yang berfungsi sebagai atribut produk wisata menjadi satu rangkaian aktivitas pariwisata yang terpadu dan memiliki tema tertentu sesuai dengan karakteristik desa (Murdianto,2011). Desa wisata merupakan suatu wilayah pedesaan yang menawarkan keaslian baik dari segi sosial budaya, adat-istiadat, keseharian, arsitektur tradisional, struktur tata ruang desa yang disajikan dalam suatu suatu bentuk integrasi komponen pariwisata antara lain seperti atraksi, akomodasi dan fasilitas pendukung (Zakaria dan Suprihardjo, 2014). Dalam karakteristik suatu desa yang memiliki kearifan lokal yang dikembangkan menjadi potensi wisata agar mampu memberikan daya tarik bagi wisatawan lokal maupun wisatawan asing dengan memanfaatkan keunikan dan keaslian berupa ciri khas pedesaan.

\subsection{Fasilitas Umum}

Fasilitas umum merupakan syarat utama agar suatu desa wisata dikunjungi oleh wisatawan. Wisatawan akan tidak akan berkunjung kembali bila fasilitas yang tersedia tidak ada atau kondisinya tidak mantap. Fasilitas pada daerah wisata terdiri dari sarana pokok keparawisataan, perusahaan perjalanan wisata, hotel (penginapan), sarana pelengkap (golf course,boating facilities), sarana penunjang (souvenir shop), Prasarana umum (jalan raya,jembatan,transportasi laut,darat,dan udara, air bersih,listrik,rumah sakit,apotek) (Yoeti, 2005). 


\section{Metodologi}

Metode yang dilakukan dalam penelitian ini adalah metode kualitatif dengan melakukan pengumpulan data melalui proses observasi dan wawancara. Penelitian ini juga melakukan kajian putaka mengenai fasilitas umum. Untuk memperkuat hasil penelitian dilakukan studi kasus terhadap dua desa yaitu desa sade di Nusa Tenggara Barat, desa penting sari di Yogyakarta dan desa kutuh di Badung Bali. Data-data yang dubutuhkan pada penelitian ini merupakan data primer berupa dokumentasi dan hasil wawancara kepala desa sedangkan data skunder berupa hasil studi literatur. Sehingga mengahasilkan potensi dan solusi kawasan perencanaan fasilitas pada Desa Tongging.

\section{Hasil dan pembahasan}

Desa Tongging sebagai daerah tujuan wisata yang sudah sejak lama dikunjungi oleh wisatawan ternyata minim fasilitas. Hal ini ditandai bahwa desa tongging belum memiliki fasilitas mendasar untuk menjadi daerah tujuan wisata. Desa ini tidak mempunyai Mesjid atau musholla untuk tempat beribadah umat Islam.Toilet umum hanya ada satu terdapat pada ujung dermaga.

Fasilitas jalan utama Desa Tongging yang sejak tahun 2018 berubah status dari jalan Kabupaten menjadi jalan Provinsi hanya memiliki lebar 4 meter sampai dengan 5 meter.Dengan kondisi ini jalan sulit untuk dilewati oleh Bus Pariwisata. Sedangkan jumlah kedatangan wisatawan meningkat bila Bus Umum dapat masuk melewati akses jalan yang ada. Selanjutnya terdapat 3 tikungan yang harus diperlebar agar kenderaan terutama kenderaan Bus bisa melewati tikungan dengan aman dan nyaman.

Dengan jumlah wisatawan yang meningkat perlu dibangun tempat beribadah umat islam seperti musholla atau Mesjid.Namun sebaiknya dibangun Mesjid karena kapasitas yang lebih besar dibandingkan Musholla. Sebagai daerah mayoritas penduduknya beragama Kristen, di desa ini sudah terdapat dua unit Gereja.
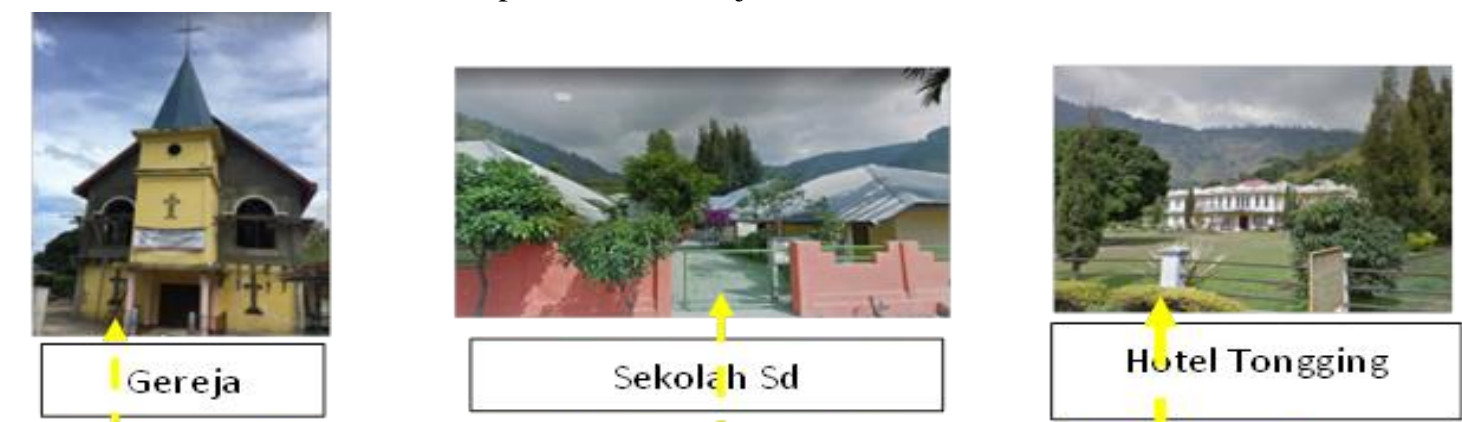

Hutel Tongging
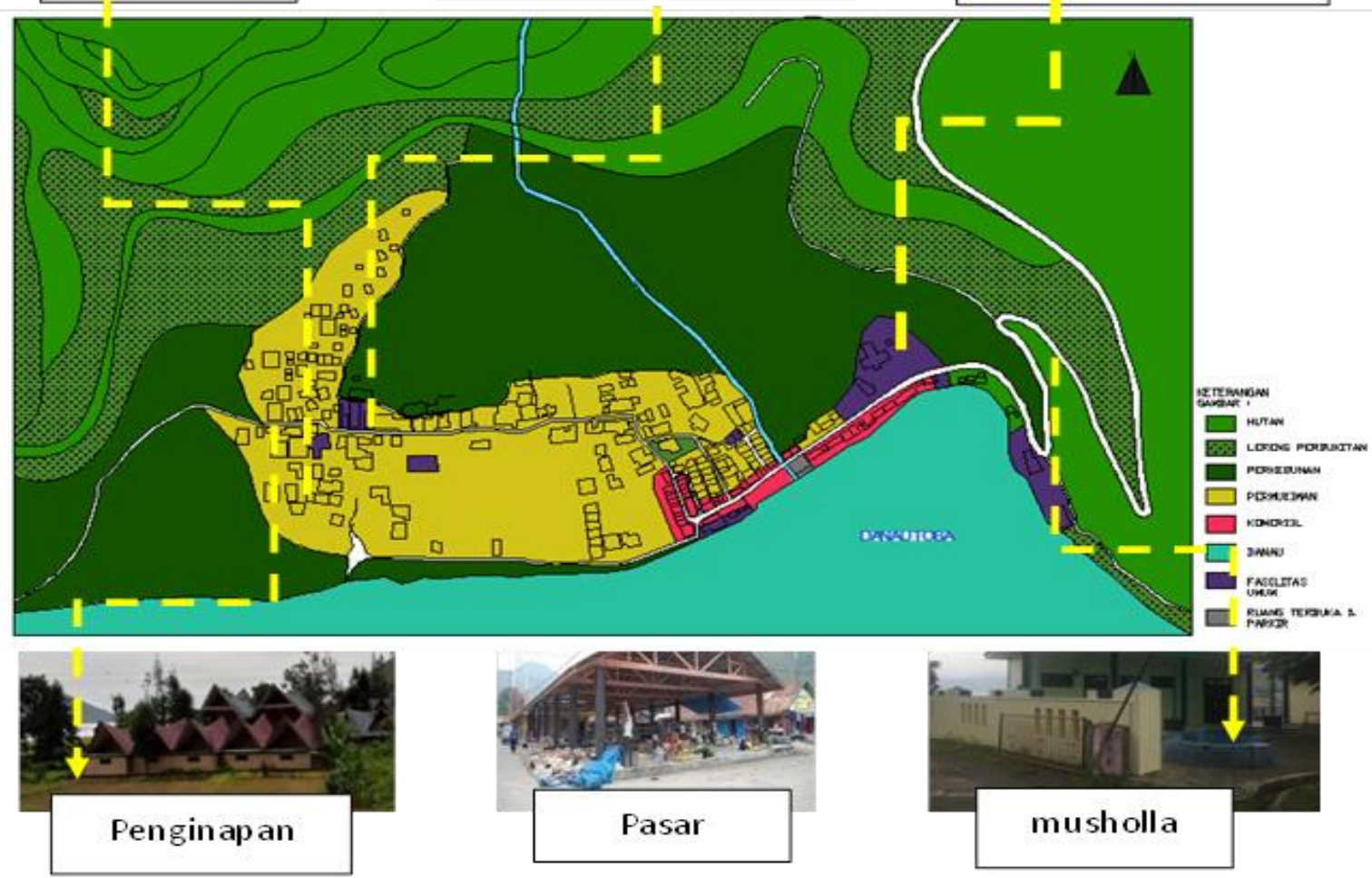
Sedangkan perbandingan kasus di dusun Sade terdapat beberapa Fasilitas umum antara lain Mesjid di sudut desa. Untuk skala desa Sade mesjid beratapkan jerami ini mungkin sudah cukup. Namun untuk kenyamanan wisatawan sebaiknya di perbesar agar mampu menampung wisatawan yang ingin sholat. Fasilitas lain adalah Lumbung Padi dan Bruga yaitu tempat bermusyawarah warga desa Sade (detiktravel,2019)

Di desa Pentingsari, wisatawan yang datang akan difasilitasi oleh penginapan berupa rumah-rumah penduduk setempat. Dengan menginap di rumah penduduk, para wisatawan dapat merasakan kehidupan sehari-hari masyarakat pedesaan. Wisatawan pada desa Pentingsari mendapatkan pelayanan penginapan pada rumah penduduk yang telah disediakan, setiap wisatawan harus membayar 70.000 untuk bisa menikmati desa wisata Penting sari(visitingjogya,2017). Sedangkan di Desa Kutuh khususnya di pantai Pandawa telah memiliki akses jalan yang baik. Kondisi jalan yang mantap. Desa Kutuh juga memiliki musholla untuk tempat beribadah umat islam (katadata,2019)

Fasilitas umum pada desa Tongging merupakan hal yang penting, fasilitas umum yang tersedia di desa ini yaitu gereja, sekolah, hotel, wisma, pasar, dan mushola. Fasilitas ini merupakan fasilitas yang bisa digunakan oleh masyarakat desa tongging dan pengunjung yang berkunjung. Sedangkan Fasilitas penting yang perlu dibangun antara lain adalah Mesjid atau Musholla,Toilet umum dan pelebaran jalan.

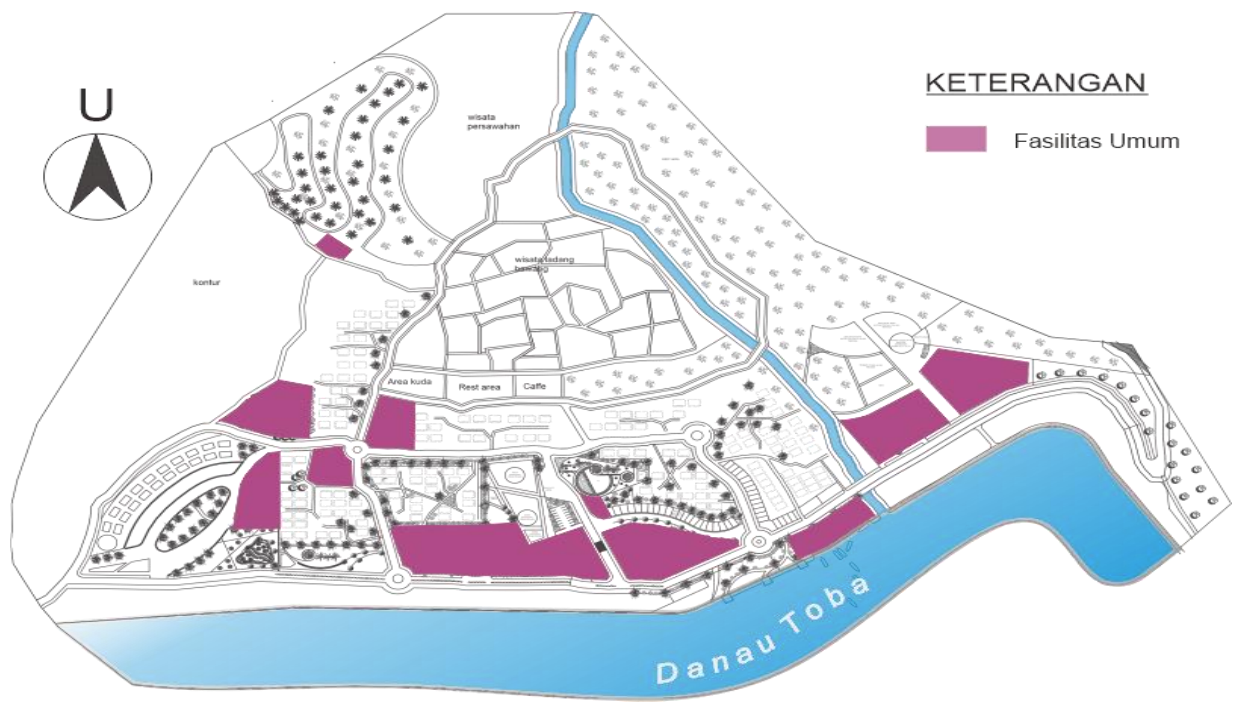

Gambar 3.Rencana Fasilitas umum pada Desa Tongging

\section{Kesimpulan}

Untuk mendukung Pariwisata di Desa Tongging perlu dilakukan perencanaan fasilitas umum yang terdiri dari jalan, toilet dan Musholla.Fasilitas ini diyakini mampu untuk memberikan rasa nyaman kepada para wisatawan yang berkunjung ke Desa Tongging. Selanjutnya perancangan terhadap fasilitas-fasilitas tersebut harus memperhatikan jumlah wisatawan yang ditargetkan berkunjung ke daarah wisata tersebut secara berkelanjutan untuk meningkatkan kesejahteraan masyarakat Desa Tongging.

\section{Referensi}

[1] Hermawan, H. (2016). Dampak pengembangan Desa Wisata Nglanggeran terhadap ekonomi masyarakat lokal. Jurnal Pariwisata, 3(2), 105-117.

[2] Murdiyanto, E. (2011). Partisipasi masyarakat dalam pengembangan desa wisata Karanggeneng, purwobinangun, pakem, Sleman. Jurnal Sosial Ekonomi Pertanian dan Agribisnis, 7(2), 91-101.

[3] Oka A. Yoeti, 2005. Perencanaan strategis pemasaran daerah tujuan wisata. Jakarta: penerbit Pradnya Paramita

[4] Zakaria, F., \& Suprihardjo, R. (2014). Konsep Pengembangan Kawasan Desa Wisata di Desa Bandungan Kecamatan Pakong Kabupaten Pamekasan. Jurnal Teknik ITS, 3(2), C245-C249. 